\title{
Experimental Study of Microwave Attenuation in a Compartment Fire
}

\author{
Sang Gi Hong ${ }^{1} \cdot$ Hakjune Lee ${ }^{2} \cdot$ Hoesung Yang $^{1} \cdot$ Junho Jin $^{1} \cdot$ Hyesun Lee $^{1} \cdot$ Kangbok Lee $^{1, *}$
}

\begin{abstract}
In this letter, we show the experimental results of microwave attenuation characteristics for representative communication frequencies (UHF, public safety long-term evolution [PSLTE], LoRa, Wi-Fi, and LTE) in a compartment fire. We used kerosene, lumber, and urethane foam as fuels, which can be easily found in homes, and measured the signal intensity with three antenna heights to investigate the effect of the flame and smoke. In the compartment environment, the ionized particles were the dominant attenuation factor of the signals. Furthermore, measurements revealed that the attenuation depends on frequencies and fuel types. In particular, large attenuation was observed at particular frequencies when burning lumber and urethane foam.
\end{abstract}

Key Words: Ash Particle, Attenuation, Ionized Particle, Plasma, Propagation.

\section{INTRODUCTION}

As urban buildings have become complex, compartment fires have become significant problems in firefighting. One of the well-known difficulties is wireless communication disconnecting when a fire breaks out. Fire in a building with a complex structure can detrimentally affect the quality of communication, threatening the safety of firefighters and residents.

Various studies of microwave attenuation due to flame and ash have been published [1-8]. These studies can be categorized by the effects of plasma and ash. The effects of plasma on microwaves have been investigated in [1-4]. The absorption and dispersion characteristics of microwaves in ionized gases have been theoretically discussed [1] and evaluated through experiments [2]. In [3], the effects of fire on microwave propagation are presented. Three frequency bands, $180 \mathrm{MHz}, 400 \mathrm{MHz}$, and $900 \mathrm{MHz}$, were selected, and the attenuated characteristics of each band are shown. The experiments reveal that attenuation characteristics are different at each frequency band, and they depend on the fuel and chemical additives.

Furthermore, the ash produced by fire also contributes to the attenuation of the intensity of microwaves [5-7]. With the capability of a radar system to detect the plume of ash, the electric properties of ash were studied. Complex dielectric modeling for fire ash particles over the X-band were introduced [5]. Measurements of the effects of moisture and temperature on ash over the $\mathrm{X}$-band were also reported [7]. These papers show how to obtain eucalypt ash samples, including adjusted moisture and empirically modified modeling.

In [8], the propagation and attenuation constants were theoretically derived when a wave propagated through the plasma. Moreover, the theory was applied and verified in a bushfire. In this letter, we focus on the attenuation of electromagnetic waves in an indoor fire environment. Compartment fires of various fuels were designed and implemented, and the effects over the following five representative frequencies were investigated: ultra-high frequency (UHF, $430 \mathrm{MHz}$ ), public safety long-term evolution (PSLTE, $700 \mathrm{MHz}$ ), long range (LoRa, $900 \mathrm{MHz}$ ), Wi-Fi (2.4

Manuscript received September 14, 2020 ; Revised November 1, 2020 ; Accepted February 3, 2021. (ID No. 20200914-144J)

${ }^{1}$ Defense \& Safety ICT Research Department, Electronics and Telecommunications Research Institute, Daejeon, Korea.

${ }^{2}$ Department of Electrical and Computer Engineering, University of Massachusetts Amherst, Amherst, MA, USA.

"Corresponding Author: Kangbok Lee (e-mail: kblee@etri.re.kr)

This is an Open-Access article distributed under the terms of the Creative Commons Attribution Non-Commercial License (http://creativecommons.org/licenses/by-nc/4.0) which permits unrestricted non-commercial use, distribution, and reproduction in any medium, provided the original work is properly cited.

(c) Copyright The Korean Institute of Electromagnetic Engineering and Science. 
$\mathrm{GHz}$ ), and long-term evolution (LTE, 2.6 GHz). Based on our experiment, we found that the plasma of the flame had a more dominant effect on microwave attenuation than smoke. Also, our results show that attenuation quantities depend on the type of fuel and frequency.

\section{EXPERIMENTAL SETTING}

In our experiments, we measured the variation in intensity of microwave signals over time. The setting of our experiments is shown in Fig. 1. The RF signal, which consisted of five frequently used frequencies-430 MHz (UHF), $700 \mathrm{MHz}$ (PS-LTE), $900 \mathrm{MHz}$ (LoRa), $2.4 \mathrm{GHz}$ (Wi-Fi), and 2.6 GHz (LTE), was generated by a signal generator, an Agilent E4438C. A pair of UWB log-periodic antennas, R\&S HL040, covering a wide bandwidth from $400 \mathrm{MHz}$ to $3 \mathrm{GHz}$ with a directional gain $>5$ $\mathrm{dBi}$, was assigned in order to transmit and receive microwave signals in the line-of-sight. The effects of the fire were measured at three antenna heights: $0.7 \mathrm{~m}, 1.2 \mathrm{~m}$, and $2 \mathrm{~m}$. A laptop recorded the intensity variation measured by a spectrum analyzer.

The compartment consisted of an iron frame, wood outer wall, and plaster inner wall. The thicknesses of both the inner and outer walls were $1 \mathrm{~cm}$, and the total size of the compartment was $2 \mathrm{~m} \times 2 \mathrm{~m} \times 2.3 \mathrm{~m}$ (width $\times$ length $\times$ height). The loss of the inner and outer walls can be ignored because the loss tangent of plaster and wood is nearly zero within the experimental frequency range. At the center of the compartment, the fuel heap occupied an area of $0.7 \mathrm{~m} \times 0.7 \mathrm{~m}$. We chose three types of main fuel heap - kerosene, lumber, and urethane foam - in the respective experiments, as they readily burn during a household fire. For easy ignition, a small amount of kerosene was added to the experiments that involved lumber and urethane foam.

\section{EXPERIMENTAL RESULTS}

Our experimental scenes over time are presented in Fig. 2. After ignition, flames rapidly spread, and as time passed, the size of the flame (ionized particle) gradually increased with denser smoke (ash particle) at the top of the compartment. For the experiments involving lumber and urethane, the added kerosene accelerated the ignition, and thus, the fuel heaps kindled a fire in a short amount of time. Due to the risk of explosion, the door was opened to reduce the pressure inside the compartment. Neverthe-

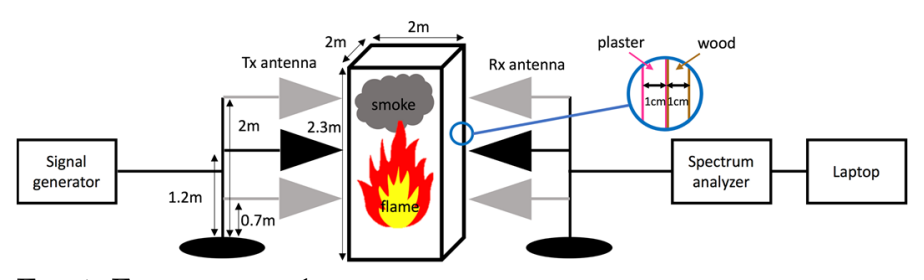

Fig. 1. Experiment schematic.

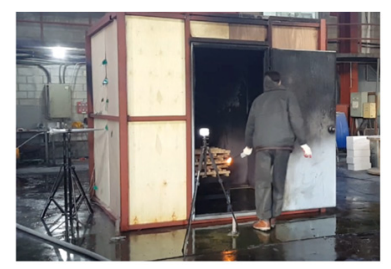

(a)

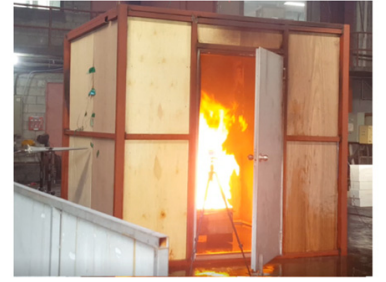

(b)

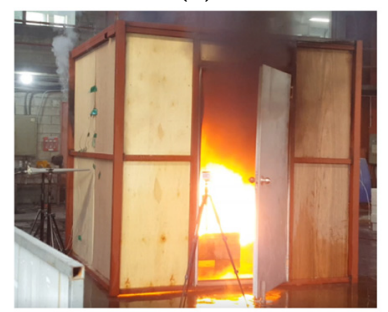

(c)

Fig. 2. Scenes from the experiment over time: (a) 0 second, (b) 75 seconds, and (c) 150 seconds.

less, the density of ash particles increased quickly inside the space over time. We measured the attenuation of the signal at three antenna heights to ascertain the effect of each part of the fire.

Fig. 3 presents the signal intensity attenuation corresponding to fuel type and antenna height. First of all, kerosene in the 0.7 $\mathrm{m} \times 0.7 \mathrm{~m} \times 0.4 \mathrm{~m}$ (width $\times$ length $\times$ height) bucket was used as fuel, and it burned explosively from the initial ignition. The height of the flame was maintained at about $1.5 \mathrm{~m}$ from ignition until the fire was extinguished. Also, smoke filled the compartment fully as time passed. At antenna heights of $0.7 \mathrm{~m}$, $1.2 \mathrm{~m}$, and $2 \mathrm{~m}$, the radio waves passed through the lower part of the flame, the upper part of the flame, and the smoke, respectively. At all antenna heights, there was no remarkable attenuation $>2$ $\mathrm{dB}$ for all five frequencies. Rather, $\mathrm{Wi}-\mathrm{Fi}$ frequency intensified when the antenna height was $0.7 \mathrm{~m}$ and $1.2 \mathrm{~m}$. The negative values of attenuation seem to have been caused by the constructive interference of diffracted waves with changed propagation constants [8], while propagating through the fire.

Second, lumber was used as fuel, piled to a height of $0.7 \mathrm{~m}$ on top of the bucket. The size of the flame and the density of the smoke gradually increased with time. When the antenna height was $0.7 \mathrm{~m}$, propagation passed through the piled lumber and flame, and obvious attenuations of UHF and LTE frequencies were observed. Maximum attenuations were $6.1 \mathrm{~dB}$ and $2.5 \mathrm{~dB}$, respectively. At an antenna height of $1.2 \mathrm{~m}$, the propagation path was mainly through the flame (plasma) just above the lumber. The PS-LTE and LoRa frequency signals attenuated sig- 


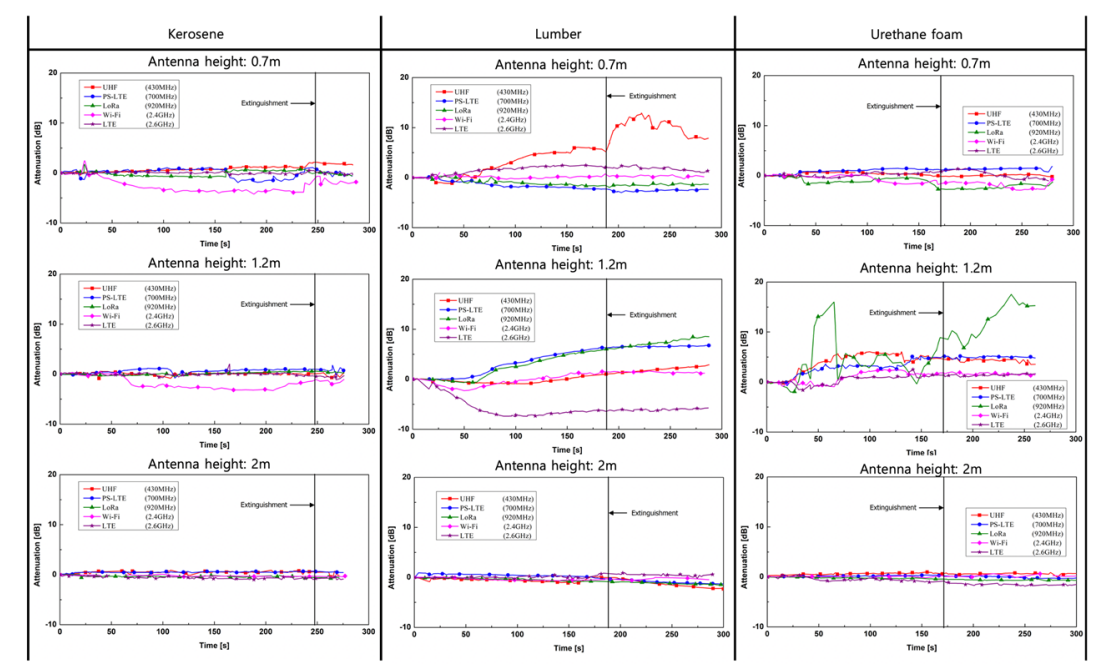

Fig. 3. Attenuation of the five frequencies with respect to fuel types and antenna heights.

nificantly up to $5 \mathrm{~dB}$. However, attenuation was not observed to be $<1 \mathrm{~dB}$ when the antenna height was $2 \mathrm{~m}$.

Finally, the attenuation of signal strength during the burning of urethane foam was measured. Urethane foam with a size of $0.8 \mathrm{~m}$ $\times 0.8 \mathrm{~m} \times 0.6 \mathrm{~m}$ (width $\times$ length $\times$ height) was placed on the bucket (height of $0.4 \mathrm{~m}$ ) and used as fuel. When the antenna height was $0.7 \mathrm{~m}$, the line of sight signal path passed through the urethane foam and flames on the surface of the foam. There was no apparent impact from the flames since the electromagnetic waves passed through the thin flame on the urethane foam surface. With an antenna height of $1.2 \mathrm{~m}$, the presence of a fire appeared to have a large effect. For all the frequencies, attenuations through the plasma over $2 \mathrm{~dB}$ were observed, and in particular, the maximum attenuation of UHF, PS-LTE, and LoRa were $6.06 \mathrm{~dB}, 5.20 \mathrm{~dB}$, and $16.0 \mathrm{~dB}$, respectively. On the other hand, at the five frequencies, it was attenuated slightly by smoke at the top of the compartment (i.e., antenna height $=2 \mathrm{~m}$ ). Thus, the attenuation of the flame mainly attributes to the effect of ionized particles near the flame. Furthermore, the attenuation coefficient [8] at the LoRa frequency, in particular, would be much greater than the ones at the other frequencies.

\section{CONCLUSION}

In this experiment, we measured the attenuation of frequencies often used in wireless communication in burning compartments. Materials often found indoors were employed as fuel. We found that attenuation patterns differed greatly depending on the height of antenna, and flame created greater attenuation than ash. When we burned kerosene, no major attenuation was observed; however, large attenuations caused by flames from burning lumber and urethane foam were detected at particular frequencies. In the near future, we will provide simulations and theoretical analyses of indoor fires and the electromagnetic attenuation caused by flames in order to broaden our understanding of the effects of compartment fires.
This research was supported by the Development of Customized Contents Provision Technology for Realistic Disaster Management Based on Spatial Information Program funded by the Ministry of the Interior and Safety of the Korean government (No. 21DRMS-B146826-04).

\section{REFERENCES}

[1] H. Margenau, "Conduction and dispersion of ionized gases at high frequencies," Physical Review, vol. 69, no. 9-10, pp. 508-513, 1946.

[2] J. Schneider and F. W. Hofmann, "Absorption and dispersion of microwaves in flames," Physical Review, vol. 116, no. 2,pp. 244-249, 1959.

[3] J. Boan, "Radio experiments with fire," IEEE Antennas and Wireless Propagation Letters, vol. 6, pp. 411-414, 2007.

[4] D. Letsholathebe and K. Mphale, "Absorption of microwaves in low intensity eucalyptus litter fire," Journal of Electromagnetic Analysis and Applications, vol. 7, pp. 217-224, 2015.

[5] R. R. Rogers and W. O J. Brown, "Radar observations of a major industrial fire," Bulletin of the American Meteorological Society, vol. 78, no. 5, pp. 803-814, 1997.

[6] T. Baum, L. Thompson, and K. Ghorbani, "A complex dielectric mixing law model for forest fire ash particulates," IEEE Geoscience and Remote Sensing Letters, vol. 9, no. 5, pp. 832-835, 2012.

[7] T. C. Baum and K. Ghorbani, "Measurements on the effects of moisture on the complex permittivity of high temperature ash," IEEE Transactions on Microwave Theory and Techniques, vol. 64, no. 2, pp. 607-615, 2016.

[8] M. Heron and K. Mphale, "Radio wave attenuation in bushfires: tropical cyclones and other severe atmospheric conditions," School of Mathematical and Physical Sciences, James Cook University, Douglas, Australia, 2004. 